\title{
Apontamentos para uma educação como exercício de espanto
}

Notes for an education as an exercise of astonishment

\author{
Luan Alves dos Santos Ribeiro ${ }^{1}$
}

\section{Resumo}

O presente ensaio tem por objetivo fazer apontamentos ontológicos acerca dos fundamentos da educação. Para tal, seguiremos a via do pensamento de Martin Heidegger, adentrando no âmbito da questão do ser (Seinsfrage). Para cumprir tal tarefa, subdividiremos o trabalho em três momentos distintos. Primeiramente, apresentaremos algumas críticas à educação como transmissão de conhecimento, como ensino humanista e como educação técnica. Após, apresentaremos alguns elementos basilares do pensamento heideggeriano. Por fim, faremos algumas reflexões e indicações de ordem hermenêutica e de ordem prática sobre a educação afim de pensarmos a sua essência (Wesen) como um perpétuo exercício de espanto.

Palavras-chaves: Ontologia. Fundamentos da Educação. Espanto.

\begin{abstract}
This essay aims to make ontological notes about the fundamentals of education. To this end, we will follow the path of Martin Heidegger's thinking, based on the scope of the question of being (Seinsfrage). To do this work, we will subdivide the study into three distinct moments. First, we will present some criticisms about education as knowledge transmission, as humanistic teaching, and as technical education. Then, we will present some fundamental elements of Heideggerian thinking. Finally, we will provide some reflections and indications of a hermeneutic and practical nature about education to think about its essence (Wesen) as a perpetual exercise of astonishment.
\end{abstract}

Keywords: Ontology. Fundamentals of Education. Astonishment.

\footnotetext{
${ }^{1}$ Doutorando em Filosofia pela Universidade Federal do Rio Grande do Sul.
} 
Introdução

O seguinte trabalho visa fazer alguns apontamentos sobre uma possível leitura dos fundamentos da educação à luz do pensamento de Martin Heidegger (1889-1976) e, assim, à luz da questão do ser (Seinsfrage). Desde já precisamos ter em mente, como âmbito diretor de nossa reflexão, que na relação educador-educando há sempre em curso por parte de quem educa uma dada concepção do sentido do ser, do homem, da existência, do conhecimento e, da mesma forma, da educação. Queremos dizer, uma pré-compreensão ontológica, antropológica, existenciária, gnosiológica e educacional que na maior parte das vezes não habita na luz da reflexividade. É nesse sentido que tal entendimento calcado numa compreensão de ser repleta de conceitos penumbrosos se transforma em uma compreensão norteada por pré-conceitos. Pré-conceitos que, por sua vez, estão constitutivamente na base da prática pedagógica.

É nessa acepção que desejamos aqui, a partir da consideração dos fundamentos da educação, indicar a nível propedêutico caminhos para uma ação educacional que considere o homem não como um ente fechado, mas sim como um ente aberto para sempre novas possibilidades, queremos dizer, como um ente que pode tornar-se si mesmo. Heidegger se ocupou da elucidação das estruturas a priori da existência em sua intrínseca e constitutiva relação com o ser, sem a qual algo como a educação não seria possível. Tendo como ponto de partida esses modos de ser, objetivamos aqui pensar a educação pela via da Seinsfrage; questão através da qual podemos questionar tanto o sentido do homem, da existência, do conhecimento e da educação.

Iniciaremos com uma sucinta crítica a três concepções de educação, a saber, o ensino calcado na transmissão de conhecimento, o ensino humanista enquanto aquele que se funda numa compreensão fechada da essentia humana e o ensino técnico. Após, apresentaremos alguns elementos basilares do arcabouço teórico heideggeriano para, por fim, fazermos algumas indicações de ordem interpretativa e de ordem prática sobre as 
possíveis relações entre a questão do ser e a educação a fim de abrirmos margem para um entendimento do ensino enquanto um exercício de espanto. Objetivamos, assim, deslocar a educação para a região do que Aristóteles caracterizou como o princípio da filosofia, o thaumázein: demorar-se diante do que nos causa estranhamento na busca por uma compreensão. Isso, é claro, no que ainda nos é permitido, enquanto educadores e educandos na era da maquinação do mundo, abarcar desse estado de ânimo (Stimmung). Assim, dizemos thaumázein não por uma correspondência efetiva, mas sim por uma vizinhança entre o espanto e o que aqui desejamos dizer.

\section{A educação à luz do espanto}

O pensamento heideggeriano nos permite, enquanto pensamento do ser (ontologia), conceber a filosofia como o saber acerca do fundamento, pois ela questiona o ser mesmo da coisa de que pergunta o pensamento. Dessa maneira, se pensamos a biologia, devemos desde já pensar o que significa o ser do ser-vivo questionado; se pensamos a sociologia, devemos do mesmo modo indagar pelo ser do ser-social a que perguntamos; se pensamos a educação em sua modalidade formal, desde já precisamos esclarecer o ser-educador-educando, a natureza dessa relação, que nos dá a possibilidade de falarmos em educação.

Quando um educador está diante dos educandos já está em jogo uma concepção enraizada pela tradição, assim como, pelas afirmações e negações abertas pela própria história (Geschichte) do que é o homem, do que é o ensino, do que é ou não fundamental e sagrado, possível ou impossível. Em suma, há um mundo (Welt) que enquanto horizonte significante determina as vias mesmas da existência concreta. Pensar através do saber acerca desse fundamento é, dessa forma, pensar o ser, o homem, a existência, o conhecimento, tal como uma possível educação construída a partir de um cuidado, de um zelo amoroso, no que tange à constitutiva abertura criadora daquilo que somos. Partimos, assim, do ontológico, isto é, das estruturas determinantes do modo de ser daquilo que nós mesmos somos, para o ôntico, a saber, a encarnação que cada um é dessas estruturas. 
Dessa maneira, perguntamos ao pensarmos a educação pelo que está fundamentalmente em jogo na canção do ensino cantada e bailada pelo e entre educador e educando. Visamos com isso trazer à luz os seus alicerces que situamos, a partir da óptica heideggeriana, no âmbito da maravilha e do poético: experiência viva de abandono do óbvio para ver, de modo mais fundamental, o mundo.

De forma preliminar, podemos considerar o espanto, ou o que nós contemporâneos ainda podemos abarcar desse estado de ânimo (Stimmung), que os gregos chamavam thaumázein, enquanto um abalo que se constitui como motor da travessia de um estado para o outro, do visto para o ainda não-visto. Em suma, do obscuro e indeterminado do não-saber ou de um saber precário acerca de algo em direção à claridade de um caminho que, enquanto caminho de conhecimento, não pode deixar de ser, perenemente, um lusco-fusco, um espaço de jogo aberto para um sempre novo espanto. Por poético, de antemão e na aproximação que aqui nos interessa, é-nos permitido considerar o dizer que elabora revelando o inabitual por detrás do habitual, de modo que o seu dizer antes de transmitir uma informação faz-se revelador de assombros, demiurgo de epifanias. É nesse sentido que podemos entender em termos gerais a afirmativa heideggeriana de que "toda a arte é, na sua essência, poesia [Dichtung]" (HEIDEGGER, 2014a, p.77). Tratam-se, a maravilha e o caráter poético, de elementos fundamentais nos desdobramentos do pensamento heideggeriano e através dos quais podemos pensar a educação.

Nas palavras de Aristóteles em Metafísica I, 2, 928b: "De fato, os homens começaram a filosofar, agora como na origem, por causa da admiração [thaumázein]" (2002, p. 11). É-nos permitido dizer o mesmo da educação dado seu constitutivo movimento de passagem do desconhecido para o conhecido: exercício por excelência do espanto. Desse modo, a sua real efetividade concerne, visto por esse ângulo, ao dinâmico admirar-se suscitado na interpretação de mundo daquele que se atreve a conhecer: educando e educador. Nessa perspectiva, educar-se é residir nos fundamentos já fundados, abrindo-se, por sua vez, para uma reinterpretação 
do mundo mediante o que já foi pensado de modo a ultrapassá-lo - ato que se desvela privilegiadamente na relação educador-educando, embora não encontre somente aí o seu lugar. O fundamento se dá no diálogo - seja através do professor ou do livro, por exemplo -, a ultrapassagem, por sua vez, na interpretação considerada como espaço de criação daquele que conhece. Ambos, a saber, filosofia e educação são, dessa maneira, exercício de maravilhar-se. Admiração, espanto, maravilha, assim, enquanto traduções do thaumázein nos ajudam a nomear a maneira como aqui desejamos pensar a educação.

Visamos com tal problematização rumar para uma compreensão que leve em consideração a experiência ${ }^{2}$ que é efetivamente o que nos acontece e nos toca, de modo a considerá-la "como uma expedição em que se pode escutar o inaudito" [...], para romper com os sistemas de educação que dão o mundo já interpretado, já configurado de determinada maneira, já lido, e, portanto, ilegível”. (LARROSA, 2017, p. 16). Falamos aqui da experiência não no sentido subjetivista, mas sim na acepção de experienciar a constituição da própria ek-sistência enquanto abertura para o ser e para a sua polissemia constitutiva. Educar, assim, torna-se abalo mediante o novo não antes ouvido ou visto de tal forma; admiração e metamorfose, assim como é uma obra de arte. Em síntese: travessia de si para si mesmo; invenção da própria ipseidade em confronto com a alteridade do mundo. Lemos:

Através de um véu, há sempre outro véu; atrás de uma máscara, outra máscara; atrás de uma pele, outra pele. $\mathrm{O}$ eu que importa é aquele que existe sempre mais além daquele que se toma habitualmente pelo próprio eu: não está para ser descoberto, mas para ser inventado; não está para ser

\footnotetext{
${ }^{2}$ Como afirma Larrosa em Notas sobre a experiência e o saber da experiência: "A palavra experiência vem do latim experiri, provar (experimentar). A experiência é em primeiro lugar um encontro ou uma relação com algo que se experimenta e se prova. $\mathrm{O}$ radical é periri, que se encontra também em periculum, perigo. A raiz indo-europeia é per, com a qual se relaciona antes de tudo a ideia de travessia, e secundariamente a ideia de prova. Em grego há numerosos derivados dessa raiz que marcam a travessia, o percorrido, a passagem: peirô, atravessar, pera, mais além, peraô, passar através, perainô, ir até o fim, peras, limite.". (LARROSA, 2002, p. 25).
} 
realizado, mas para ser conquistado; não está para ser explorado, mas para ser criado. (LARROSA, 2017, p. 14).

Nessa acepção, o ensino não pode ser considerado sob a perspectiva da mera transmissão do conhecimento marcado pela cultura do silêncio do educando como na educação-bancária apontada por Paulo Freire, onde "o saber é uma doação dos que se julgam sábios aos que julgam nada saber" (2019, p.81), de modo que o educador se torna o depositário de um conhecimento que narra conduzindo os educandos "à memorização mecânica do conteúdo narrado" (FREIRE, 2019, p. 80). Antes, a educação aqui vislumbrada deve alicerçar-se no modo de ser próprio daquilo que somos, um sempre vir-a-ser, passando, desse modo, por uma rigorosa elucidação ontológica - o ponto basilar da filosofia de Heidegger. Por conseguinte, ela deve ser dinâmica, imprevisível, misteriosa e potente tal como as vias concretas da existência humana, reconhecendo que "onde há vida, há inacabamento" (FREIRE, 2007, p, 50) e, assim, há experiência criadora.

A educação poética deve, nesse sentido, se fundar em um "suspender o automatismo da ação, cultivar a atenção e a delicadeza, abrir os olhos e os ouvidos, [...], ter paciência e dar-se tempo e espaço" (LARROSA, 2002, p. 24), o que não pode ocorrer no ensino bancário, dada a sua própria natureza de transmissora veloz de informação. Natureza que não alcança, enquanto fruto amargo de uma sociedade calcada no acúmulo de saberes, a genuína experiência educadora. Heidegger, com a radicalidade de seu pensamento acerca do homem, da experiência e do sentido, pode nos ajudar a pensar essas questões em bases ontológicas. Em suas palavras: "Fazer uma experiência com algo [...] significa que esse algo nos atropela, nos vem ao encontro, chega até nós, nos avassala e transforma" (HEIDEGGER, 2003, p. 121).

A partir do pensamento heideggeriano, podemos, do mesmo modo, refletir criticamente sobre as bases da educação humanista. Tal educação se funda em um entendimento metafísico do homem, isto é, na pressuposição 
de uma natureza que antecede a sua existência concreta, determinando-o irremediavelmente em seu ser por constituir exatamente o seu ser fixado. Como nos diz Heidegger em Carta Sobre o Humanismo: "Todos os tipos de humanismo [...] pressupõem a 'essência' mais universal do homem como óbvia e evidente" (2008c, p. 335).

Dentre as mais velhas e imponentes definições metafísicas da essência do homem, temos a zôon lógon échon de Aristóteles, traduzido para o latim como animal rationale e para o português como animal racional. Trata-se do homem concebido como o animal que se realiza no puro exercício de sua racionalidade. Numa perspectiva ontológica, trata-se de um equívoco perigoso que esquece a abertura para o mundo sempre indefinível e transformadora que constitui o homem, assim como da importância de sua emoção sempre presente, da construção viva de seu entendimento jamais totalizador, em termos gerais, de uma consideração que o veja pelas suas próprias especificidades e não como se fosse uma coisa.

A tradição humanista, aqui entendida à luz de Heidegger enquanto aquela fundada numa compreensão metafísica do ente humano, é concebida enquanto "meditar e cuidar para que o homem seja humano e não deshumano, 'inhumano', isto é, fora de sua essência” (HEIDEGGER, 2008c, p.332). ${ }^{3}$ Assim, fundando-se numa compreensão, por assim dizer, já pronta do que é o homem, ela incorre, tal como a supracitada educação-bancária, em agressões profundas ao seu vir-a-ser e à liberdade criadora de si mesmo. Ela exclui tudo o que está fora do âmbito metafísico de seu fundamento, legando aos demais o caráter de inhumano ou de humano incompleto em sua característica humanidade ${ }^{4}$.

\footnotetext{
${ }^{3}$ Em termos históricos o que aqui entendemos por educação humanista tem, no âmbito do mundo ocidental, suas origens na paidéia grega. Paideia que consolidava, ao formar para a Polis, a distinção fundamental entre o cidadão grego e os que não tinham direito às decisões da comunidade.

${ }^{4}$ Como esclarece Heidegger: "Expressamente sob seu nome, a humanitas só vem pensada e postulada pela primeira vez na época da República Romana. O homo humanitas se contrapõe ao homo barbarus. O homo humanus, aqui, é o romano, que eleva a virtus romana, enobrecendo-a pela 'incorporação' da paidéia adotada dos gregos. [...] Em sua essência, portanto, continua sendo um fenômeno especificamente romano, surgido do encontro da romanidade com a cultura da Grécia tardia. [...] Também o homo romanus da renaissance se contrapõe ao homo barbarus. Agora, no entanto, o in humano é a suposta barbárie escolástica gótica da Idade Média. [...] Isto aparece de novo no humanismo do
} 
Como nos alerta Larrosa: "Toda tradição pedagógica-humanística (aquela que se expressa nos conceitos de Paídeia, Humanitas, Bildung) implica que a educação, [...], pode ser pensada como uma relação “formativa e humanizante" (2017, p. 17). Formativa e humanizante no sentido de transmitir os conteúdos canônicos de uma cultura, assim como de formatar e conformar o homem a partir de um parâmetro ideal fora do qual habita a animalidade. Nas palavras de Heidegger:

\begin{abstract}
A palavra "bilden" formar-se, significa, por um lado, propor e prescrever um modelo. Por outro, desenvolver e transformar disposições previamente dadas. A formação apresenta ao homem um modelo para servir de parâmetro à sua ação e omissão. Toda formação necessita de um paradigma previamente estabelecido e um ideal comum de formação e garantir-lhe o domínio pressupõe uma situação inquestionável e estável em todos os sentidos. Esta pressuposição, por sua vez, há de se fundar por uma fé no poder irresistível de uma razão imutável e seus princípios.
\end{abstract} (2002c, p. 58).

A educação que aqui buscamos pensar, a partir de aspectos do pensamento de Heidegger, opõe-se veementemente a essa tradição que concebe o homem metafisicamente como um ente dotado de uma essência (essentia) permanente e, dessa maneira, determinada por uma natureza já definida. Partimos, pelo contrário, do pressuposto da sempre incompletude e imprevisibilidade do homem, tal qual da consideração de sua essência (Wesen) como abertura à pura existência situada - criação de si mesmo. Assim, podemos chamar, a partir dessa contraposição, o nosso apontamento de uma educação pós-humanista calcada em bases ontológicas. É nesse

século XVIII, sustentado por Winckelmann, Goethe e Schiller" (HEIDEGGER, 2008c, p 333). Podemos, evidentemente, reconhecer essa posição humanista segura da essentia humana, com toda a pompa de seu absolutismo e autoritarismo, na prática pedagógica hodierna. 
sentido que para Sloterdijk em Regras para o parque humano - uma resposta à carta de Heidegger sobre o humanismo:

Heidegger deixa expostas consequências abaladoras: o humanismo, em suas formas antiga, cristã e iluminista, é declarado responsável por uma interrupção de dois mil anos no pensamento; é censurado por ter obstruído, com suas interpretações apressadas e aparentemente evidentes e indiscutíveis da essência do ser humano, o surgimento da genuína questão sobre sua essência. (2000, p. 24).

Essência (Wesen) essa indefinível, aberta, vertiginosa, existente. Devir e criação incessante movida pelo motor da vida e que somente cessa, em condições normais, com a possibilidade derradeira da morte.

Quanto à educação técnica, aquela regida pelo mundo da técnica, a questão nos parece ainda mais grave, pois nela, graças às exigências do mercado e jamais do próprio ente humano, as pessoas se tornam meras coisas, porém, não coisas quaisquer, mas sim mercadorias para o jogo alienante e insano da produção ${ }^{5}$. Na perspectiva de Heidegger, podemos dizer que esse tipo de des-educação se funda na essência da técnica enquanto armação (Gestell) que se impõe como modo de compreensão do ser na contemporaneidade ${ }^{6}$.

Conforme nos esclarece Masschelein e Simons na obra Em defesa da escola - uma questão pública, a palavra escola deriva do grego skholé que indica "tempo livre, descanso, adiamento, estudo, discussão, classe, escola, lugar de ensino" (2013, p. 25) evidenciando o espaço escolar como localidade caracterizada pelo tempo livre disponível para o puro aprender. Sua raiz histórica se refere à "invenção (política) da polis grega" (MASSCHELEIN; SIMONS, 2013, p. 26) e, dessa maneira, à

\footnotetext{
${ }^{5}$ Em termos históricos a educação técnica é um fenômeno iminentemente moderno. Todavia, a partir dos objetivos do texto, empregamos aqui o termo à luz da concepção de essência da técnica enquanto Gestell segundo desenvolvido por Heidegger em termos estritamente ontológicos.

${ }^{6}$ Discorreremos sobre a Gestell mais a seguir.
} 
democratização do tempo livre para além das elites aristocráticas e militares. Nessa perspectiva, tornar o tempo livre novamente produzido se traduz como um processo de desescolarização, queremos dizer, de destituição de seu mais fundamental sentido histórico.

Diferentemente da atividade, por exemplo, em uma fábrica onde se produz um motor, na escola se visa, quando considerada a sua essência mais própria, tirar o motor de seu contexto normal, isto é, transformar o tempo produtivo em tempo de aprender o seu funcionamento. Temos aqui uma característica essencial da escola: a suspensão, que indica "tornar algo inoperante, ou, em outras palavras, tirá-lo da produção, liberando-o, retirando-o de seu contexto normal" (MASSCHELEIN; SIMONS, 2013, p. 33). É a partir da suspensão que o educando pode ser efetivamente educando em sua disponibilidade para o puro aprender, assim como, que o professor pode ser propriamente professor, ensinando e aprendendo. É assim que pode haver algo como o ensino.

Nessa acepção, o ensino técnico, onde a educação é transformada em tempo produtivo e em preparação para o mercado de trabalho, desescolariza a escola, pois ela "sempre significa conhecimento em prol do conhecimento, e a isso chamamos estudo" (MASSCHELEIN; SIMONS, 2013, p. 40). A escola funda um tempo-espaço que, de certo modo, está separado do tempoespaço da sociedade: um tempo-espaço do aprender. Assim, sem o conhecimento pelo conhecimento não pode haver, conforme tal visão, efetivamente estudo, mas algo outro à face propriamente dita de sua autêntica significação.

Sobre o pensamento nas vias do ser

Em Ser e Tempo (1927), Heidegger inicia o seu percurso pelo que se tornará o centro radiante de toda a sua indagação posterior, a saber, pela questão do ser (Seinsfrage). Seu pensamento se alicerça na distinção entre ser e ente, isto é, na denominada diferença ontológica. Dito sucintamente, o ente é o que é - o livro, a árvore, a casa - enquanto o ser se dá como aquilo 
que sempre se esquiva das nomeações totalizadoras. Assim, o ser é concebido como o horizonte de sentido e de compreensão de tudo o que é, isto é, de todo ente, mas que dada a sua polissemia foge a toda tentativa de definição - se tentamos defini-lo, devido às múltiplas possíveis enunciações sobre o mesmo ente, ele nos escapa, de forma que toda definição unívoca fere a sua própria natureza. Assim, é indicado que todo sentido que podemos atribuir sobre o ente é sempre parcial, isto é, é sempre um aspecto do ser daquele ente.

Se descerrarmos um ente qualquer através da perspectiva da biologia, da física, da química, da poética ou da filosofia, desse modo, estaremos considerando apenas um ou alguns de seus possíveis horizontes de compreensão. $\mathrm{O}$ ente mesmo, enquanto totalidade dos sentidos, foge-nos continuamente. Conforme esclarece o pensador nos Seminários de Zollikon (1964), o ser "não é algo real que se possa encontrar numa mesa, mesmo que se a desmonte em suas inúmeras partes" (HEIDEGGER, 2001, p. 34).

É através da denominada diferença ontológica que se abre, por conseguinte, as vias de um novo caminho para se pensar o homem em sua acepção mais fundamental. Heidegger o denomina, em sua privilegiada relação com o ser, de Dasein que em tradução literal significa ser-aí, no sentido de localizar o humano $(D a)$ como lugar, aí, de constitutiva abertura para o ser (Sein). Em suas palavras: "Esse ente que somos cada vez nós mesmos, [...], nós o apreendemos terminologicamente de Dasein" (HEIDEGGER, 2014c, p. 47).

Com a nova designação, o filósofo almeja efetuar uma passagem das compreensões metafísicas do homem - animal racional, eu autoconsciente, por exemplo, - que buscaram defini-lo em sua totalidade, para uma compreensão que o considere em vista de sua abertura para o ser. Do Dasein não se pode dizer o que é, mas apenas como é, queremos dizer, como ocorrem as modalidades estruturais de sua abertura para o ser. Dessa forma, o caminho seguido em Ser e Tempo é o de uma análise ontológica que evidencie os modos de ser do homem compreendido como Dasein: a morada do ser. 
Assim, enquanto ente aberto ao ser, isto é, ao horizonte de sentido e de compreensão dos entes o Dasein é o único ente capaz de se educar, de se maravilhar, de se questionar sobre aquilo que é buscando o seu fundamento. Nesse ponto, pensar a educação a partir das perspectivas abertas por esse entendimento torna-se um importante desafio na reflexão dos seus próprios fundamentos ontológicos. Heidegger nos esclarece em A Essência do Fundamento (1929):

[...] o elemento distintivo do homem consiste no fato de que ele, enquanto ser pensante, aberto para o ser, está posto em face dele, permanece relacionado com o ser e assim lhe corresponde. O homem é propriamente esta relação de correspondência, e é somente isto. "Somente" não significa limitação, mas uma plenitude. No homem impera um pertencer ao ser; este pertencer escuta o ser porque a ele está entregue com propriedade. (HEIDEGGER, 2008a, p. 141-2).

Aos modos de ser do Dasein, isto é, aos elementos estruturais de seu próprio a priori ontológico, Heidegger designa o termo existenciário (Existenzialien), diferenciando-os das categorias. Por categoria, termo oriundo da filosofia aristotélica, entende-se aqui o modo de ser dos demais entes - entes não abertos para o ser como, por exemplo, uma cadeira, uma árvore ou um animal qualquer - e que foram historicamente legados também ao Dasein, impedindo, assim, que seu efetivo modo de ser viesse à luz. Dessa forma, Heidegger caracteriza o modo de ser do homem como a sua existência, isto é, enquanto ex-sistere, no sentido de considerá-lo como um ente que está no ser (sistere) de maneira que seu próprio modo de ser está em risco (ex). O Dasein pode moldá-lo através de suas possibilidades e certamente irá perdê-lo com a sua morte.

O primeiro modo de ser característico do Dasein distinguido em Ser e Tempo, isto é, o primeiro existenciário é o encontrar-se (Befindlichkeit) 
que indica que o homem nunca está situado no mundo de maneira neutra, mas sempre o sentindo desta ou daquela forma. É nesses termos, em sentido ontológico, que devemos entender a afirmativa: “[...] o Dasein já está cada vez e sempre em um estado de ânimo [Stimmung]". (HEIDEGGER, 2014c, p. 385). Ao ontológico e estrutural que é o encontrar-se (Befindlichkeit) soma-se a sua ativação concreta que é o estado de humor (Stimmung) como, por exemplo, a apatia ou a alegria.

Pensando com Heidegger e contra Heidegger - na acepção de que subvertemos o seu dito em busca de outros caminhos - se em Ser e Tempo a angústia é localizada por Heidegger como a o encontrar-se (Befindlichkeit) privilegiado através da qual o homem pode lançar mão da aceitação de sua finitude, encontrando-se como de fato é, o afeto amoroso pode ser considerado por nós como um humor (Stimmung), derivado ôntico da estrutura ontológica, importante para a abertura das vias de uma nova relação entre educador e educando.

Falamos, então, de uma pedagogia do afeto alicerçada na abertura existenciária. Diferenciamos tal pedagogia de uma pedagogia do terror caraterizada pela autoridade autoritária do professor detentor do conhecimento e do valor do bom e do belo. Na pedagogia do terror, enquanto educação da mera transmissão de conhecimento, o educando é comumente constrangido e diminuído diante do todo poderoso detentor do conhecimento. Essa postura pode ser encontrada tanto na educação humanista, que quer conformar o homem a uma ideia já fixa de homem, quanto na educação técnica, que reduz o homem a um produto para o mercado de trabalho. Uma vez que o Dasein nunca está situado de maneira neutra no mundo, podemos explorar tal dimensão ontológica para pensar possíveis relações favoráveis ao ato pedagógico. Temos aqui um importante aceno para uma prática pedagógica.

Masschelein e Simons apontam para a importância do amor e do cuidado na prática educacional. O que, a partir de Heidegger, podemos considerar ontologicamente. Como o encontrar-se é um modo estrutural de abertura do humano para o mundo indicando que ele nunca se situa de 
maneira neutra, podemos concluir o óbvio nem sempre tão óbvio de que a prática educacional é também sempre marcada pelo sentimento e não pela pura razão metafísica. Lemos:

[...] expressado em termos conscientemente provocantes, poderíamos dizer que fazer a escola reside, em parte, no amateurismo do professor. [...] Um professor é alguém que ama o seu tema ou matéria, que se preocupa com ela e presta atenção a ela. Ao lado do "amor pelo assunto", e talvez por causa disso, também ensina por amor ao aluno. Como um amador, o professor não é apenas versado sobre algo, também se preocupa e está ativamente envolvido nesse algo. (MASSCHELEIN; SIMONS, 2013, p. 77).

O cuidado comunicativo, o zelo amoroso com os entes ali em jogo, o despertar de paixões mútuas tornam-se, quando consideradas sob essa óptica, um elemento fundamental para uma ação educacional que se traduza em (re)descobrir o mundo e efetivar possibilidades. Heidegger nos mostra que interpretamos por estarmos desde sempre situados num determinado contexto. Romper barreiras, profanar hábitos, dançar a canção de uma alteridade aberta ao novo, produzir maravilha tornam-se novas cores de um ensino que seja poesia e de uma poesia que seja ensino: passagem, travessia, desafio, dor e triunfo. O amparo do professor amoroso servirá como guia que aponta para novos caminhos e para a possibilidade de superação dos momentos mais difíceis.

Outro existenciário é o entendimento (Verstehen) que, por sua vez, indica que o Dasein está no mundo sempre o entendendo de alguma forma. Seu entendimento se refere à construção aberta pela cultura de proveniência do indivíduo concreto, mas revela, enquanto um modo de ser fundamental, uma estrutura ontológica. Lemos: "O entendimento-do-ser é ele mesmo uma determinidade-do-ser do Dasein". (HEIDEGGER, 2014c, p.59). Nessa perspectiva, é fundamental reconhecer que o educando ao entrar no processo 
de aprendizagem traz consigo sua própria bagagem. Compreender tal origem, assim como legitimá-la como caminho pedagógico deve ser, nessa perspectiva, algo basilar para um efetivo aprendizado. O saber cotidiano trazido pelo educando se torna, assim, caminho para uma prática pedagógica que considere a autonomia humana. Heidegger nos permite pensar esse caminho a partir de um viés ontológico. Temos, por conseguinte, outro aceno prático a partir da ontologia.

Outro elemento importante a ser distinguido, é que dentre todos os existenciários, o entendimento ocupa um lugar privilegiado, pois ele se desdobra nas categorias que, conforme já indicado, concernem ao saber acerca do modo de ser das coisas. Como ente dotado de entendimento, o Dasein pode, assim, conhecer não só a si e aos outros Daseins, mas os demais entes do mundo. Verstehen se refere na filosofia de Heidegger, desse modo, à condição de possibilidade do conhecimento concebido enquanto uma atitude desse ente dotado de entendimento e que somos nós mesmos.

O terceiro e último existenciário é o discurso (Rede) indicando que o Dasein sempre articula sua compreensão através de uma discursividade. Assim: "O discurso é a articulação da entendibilidade. Por isso, o discurso fundamenta a interpretação e a enunciação" (HEIDEGGER, 2014c, p. 455). É através do discurso, enquanto estrutura ontológica, que o Dasein põe em relação às possibilidades abertas pelo seu encontrar-se (Befindlichkeit) e pelo seu entendimento (Verstehen), isto é, pelo seu sentir que se entende e pelo seu entendimento que se sente.

Tal existenciário aponta, assim, para o fato de que o educando ao entrar em sala de aula - localidade por excelência da relação educadoreducando - traz consigo, através de seu próprio vocabulário, um saber articulado acerca de si e do mundo. Apropriar-se de uma linguagem inteligível para o educando a fim de, através de seu próprio dizer, gerar uma ampliação de conhecimento e de vocabulário é, dessa forma, algo fundamental para uma efetiva prática pedagógica. Os três existenciários podem se tornar, assim, ferramentas pedagógicas fundadas em um solo ontológico. 
Apesar do saber instaurado por Heidegger nos anos de produção de Ser e tempo, o autor passa, a partir da década de trinta, por uma mudança de caminhos que igualmente pode trazer importantes contribuições para nossa compreensão da educação. A essa transformação, Heidegger e os estudiosos de seu pensamento chamaram de virada (Kehre). Trata-se da passagem da analítica existenciária do Dasein para um questionamento sobre a história do ser, isto é, pelas formas como o ser foi doado, recebido e interpretado historicamente abrindo o horizonte interpretativo comum de uma época. Dessa forma, cada momento da história possui, segundo essa posição, seu próprio modo de compreensão característico sendo que em tal compreensão habitaria a unidade de um tempo histórico.

Em termos gerais, na Grécia antiga temos, segundo essa perspectiva, o ser compreendido inicialmente como physis que "é o movimento de eclosão, a emergência pensada verbalmente e dita na forma nominal [...], e é essa emergência que é ser" (ZARADER, 1999, p. 49). Posteriormente, a partir dos sistemas filosóficos de Platão e Aristóteles o ser é tomado como ente no sentido de presença, a saber, daquilo que é. Na Idade média, é compreendido como Deus, ente supremo criador. Na modernidade, através da autoconsciência cartesiana e na contemporaneidade através da essência da técnica como armação (Gestell). (HEIDEGGER, 2014b).

Heidegger quer aqui distinguir o núcleo a partir do qual o mundo é, em cada época, pensado no seu próprio processo de acontecimento. Cada era tem, segundo essa perspectiva, um fundamento determinante através do qual comumente se pensa e se vive. Atualmente, diz-nos Heidegger - em uníssono com uma gama incontável de outros pensadores - pensamos e vivemos, enquanto cidadãos do mundo contemporâneo, em vista do produzir técnico e, assim, em vista da exploração da natureza que concebe todos os entes, inclusive o homem a partir desse produzir. A educação técnica pode ser por nós compreendida, por conseguinte, como um dos sintomas dessa compreensão sendo o seu fundamento ontológico.

Grosso modo, o horizonte da essência da técnica enquanto destino (Schicksal) de nossa época, isto é, enquanto nossa determinidade de 
compreensão de ser hodierna se refere a um modo mediante o qual os entes do mundo são compreendidos sempre em vista de um para algo. Por exemplo, a pedra não é mais a pedra que repousa entre a vegetação de uma mata, mas sim o material para a construção de fábricas, igrejas, casas, escolas ou universidades. Do mesmo modo, o rio não é mais o rio repousando em seu puro estar, mas sim matéria para o funcionamento de uma hidrelétrica ou lugar para que os homens possam locomover-se em um barco ou retirar os peixes para o seu alimento. Assim, a totalidade do ente se torna uma reserva permanente. É nesse sentido que lemos em A Questão da Técnica (1953):

\begin{abstract}
A usina hidroelétrica não está instalada no Reno, como a velha ponte de madeira que, durante séculos, ligava uma margem à outra. A situação se inverteu. Agora é o rio que está instalado na usina. O rio que hoje o Reno é, a saber, fornecedor de pressão hidráulica, o Reno o é pela essência da usina. (HEIDEGGER, 2002a, p. 20).
\end{abstract}

A este modo de ver muito comum para nós, Heidegger indica, nos termos já assinalados, um modo histórico de interpretação do ser característico da nossa época. Modo que joga e somente quer jogar, isto é, modo que vê um para algo em tudo sem sequer ter uma finalidade em si mesma; finalidade para além do seu próprio jogo.

No âmbito do pensamento heideggeriano a arte é situada como local (Ort) de abertura para a possibilidade de outros modos de compreensão do ser alcançável mediante um esforço de pensamento que seja rememoração (Andenken) da sua própria história e de seus horizontes determinantes. Isso se dá, em termos sintéticos, por sua capacidade de evidenciar a esquecida polissemia do ser e a agressão que significa tratá-lo como uma coisa, sobretudo, como uma coisa em vista do mero produzir técnico.

Nesses termos e no que aqui nos cabe discernir, a virada (Kehre) heideggeriana para a história do ser abre margem para uma reflexão sobre a 
arte como localidade privilegiada de encontro do Dasein com o mistério do próprio ser. Segundo o pensador, a obra de arte ao levantar outros horizontes significativos revela a possibilidade de abertura de formas mais múltiplas e fundamentais de compreensão de mundo. A arte - que para Heidegger é em essência poesia (Dichtung): um trazer à claridade a indefinibilidade do ser - diz sem definir, sem tentar reter o todo do que algo é. Assim, ela se traduz como uma experiência que enquanto efetiva experiência nos abala, nos atravessa, colocando em xeque a totalidade de nossas concepções. Ela funda o novo mediante o desconhecido que trás à luz e que, enquanto irrompido do núcleo sempre misterioso da vida, é ainda um jogo de sombras do ser.

Sobre o espanto de ensinar e aprender

Em A Origem da Obra de Arte (1936), lemos: "Sempre que a arte acontece, isto é, quando há um início, um abalo atinge a história, a história tem início ou volta a iniciar-se”. (HEIDEGGER, 2014a, p. 83). A educação poética aqui vislumbrada tal como a arte deve ser exercício de maravilhar-se mediante o qual se evidencia o inabitual esquecido pela couraça do dito ordinário. Ação de escuta do não-dito trazido à presença através do dito. Embora não possamos nos abrir, dado o horizonte significativo em que nos inserimos, para o estado de ânimo (Stimmung) do thaumázein propriamente dita, assim o chamamos pela sua vizinhança com o que aqui almejamos dizer.

Como nos diz com tons heideggerianos Larrosa em Pedagogia Profana: "O misterioso expresso poeticamente, ao conservar seu mistério, conserva-se como uma fonte infinita de sentido" (2017, p.94). O ensino do espanto enquanto aquele que se transmuta em ensino poético é, nessa acepção, fundado em indicações, sussurros e assombros suscitados pelo diálogo entre educador e educando. Um contínuo convite para enveredar-se na polissêmica experiência da linguagem e de seus ricos horizontes: morada de todo exercício hermenêutico e, assim, núcleo do qual irrompe toda possibilidade de conhecimento. Conhecimento que, nessa perspectiva, faz- 
se a imagem e semelhança do Dasein: constitutivamente inacabado e, assim, um perene estar a caminho, um abundante expandir-se.

O educador, por sua vez, enquanto aquele que direciona a atenção do educando para determinado objeto, esclarecendo sobre o que o educando ainda não sabia, insinuando insuspeitas metamorfoses deve ser como um poeta que gera maravilha. Ele deve evidenciar o não-obvio por detrás das ambiguidades do senso-comum, trazendo o novo filosófico, poético ou científico. Educar é, visto por essa perspectiva, (re)aprender a (re)habitar o mundo e deixar aprender através de acenos à riqueza imensurável de ser.

Como nos diz Saviani em Escola e Democracia: Polêmicas de nosso tempo:

\begin{abstract}
Atualmente alguns educadores buscam rever suas posições pedagógicas à luz da fenomenologia [...]. Registrei de modo explícito essa diferença matriz ao afirmar que a referida concepção admite a existência de formas descontínuas da educação. [...] Considera-se que a educação segue o ritmo vital que é variado, determinado pelas diferenças existenciais ao nível dos indivíduos [...], na medida em que os momentos verdadeiramente educativos são considerados raros, passageiros, instantâneos. [...] Tudo o que se pode fazer é estar predisposto e atento a essa possibilidade. (1995, p. 72).
\end{abstract}

É, em termos gerais, nesse sentido que desejamos pensar aqui a educação, concebendo, por conseguinte, o processo educativo como travessia por um caminho de espantos; passagem de si para si mesmo na esfera auto-criadora e, assim, poética. A dificuldade da educação é, nesses termos, a dificuldade da própria criação autêntica de si; são as agruras que nos levam às clareiras de nosso ser. A relação educador-educando aqui esboçada é pensada no sentido de educar em favor da singularidade e não do genérico e do impessoal (Uneigentlichkeit). O ontológico, isto é, o a priori humano será o guia que abrirá espaço para a consideração da experiência 
individual, como encarnação do estrutural e do universal, sempre em jogo no processo de ensino.

Nessa acepção, o professor antes de ser um transmissor de doutrinas e um fundamentador de saberes é um companheiro mais experiente no caminho do conhecimento que acena, instiga, evidenciando o não-óbvio velado pela epiderme do dito evidente. $\mathrm{O}$ verdadeiro mestre é, assim, aquele que convida o educando a aprender. Exercício que exige paciência, escuta, ética. Tal concepção está, a nosso ver, em concordância com a raiz etimológica do termo educação oriunda da "experiência expressa no termo latino 'educare", que em sua etimologia indica um 'trazer para fora', um ‘tirar de'...” (KAHLMEYER- MERTENS, 2008, p. 40). Educação, nesses termos, é deixar aprender, sendo a revelação dos múltiplos sentidos do ser em um caminho sem chegada. Um retirar o educando de seu estado habitual, mediante a potência de insuspeitos horizontes - o que vale do mesmo modo para o educador. Por isso, o fundamental aqui reside no próprio caminhar que nos leva para fora de nós mesmos em direção ao sempre novo. A educação poética é como uma dança.

Cada vez que se olha para uma obra de arte, ela pode revelar outra face, outro aspecto ainda não trazido à luz. Assim deve se dar a educação poética enquanto educação do maravilhar-se. Temos, dessa forma, outro aceno importante: é preciso percorrer, de forma a salvaguardar a individualidade dos educandos, várias maneiras de dizer o mesmo que, enquanto dotado de múltiplas enunciações e aspectos, é concomitantemente o mesmo e o outro, relacionando os diversos dizeres em sua mútua referência com o ser: diálogo, con-versa (isto é, um versar da alteridade não autoritária, um versar com os outros).

Nessa acepção, na educação aqui apontada o educando deve ser conduzido, através de acenos e sussurros de espanto, a descobrir novos horizontes através de novos conhecimentos, assim como, através da conquista de novas perspectivas acerca do saber que já trazia consigo. Do mesmo modo, o educador aprende com esse diálogo frutífero que é aprender-ensinar e ensinar-aprender. Trata-se de uma educação que se funda 
antes numa apuração do olhar que na tomada de conclusões, pois sempre há o novo, o obscuro, o olvidado a ser trazido à luz. Exercício criativo de reinvenção de si e da vida.

Concordamos, nesse sentido, com $O$ Mestre Ignorante $^{7}$ de Rancière segundo o qual: "Não há ignorante que não saiba uma infinidade de coisas, e é sobre este saber, sobre esta capacidade em ato que todo ensino deve se fundar. Instruir pode, portanto, significar [...], forçar uma capacidade que se ignora ou se degenera a se reconhecer" (2002, p.11). A educação poética enquanto con-versar entre espantos, parte do pressuposto do valor intrínseco do saber que cada educando traz à localidade da sala de aula. Todavia, por outro lado, não podemos, a partir de uma perspectiva ontológica, compactuar com a afirmativa segundo a qual a "única insígnia que vale é a da igualdade das inteligências" (RANCIÈRE, 2002, p. 66), pois afirmar a total igualdade entre as inteligências significaria tratá-la como um categorial, lançando no mar da generalidade à individualidade cognoscitiva e existenciária de cada educando.

O Dasein é, diferentemente da posição sobre o humano defendida pelo mestre ignorante, um ente dotado de entendimento (Verstehen) que, enquanto estrutura ontológica, é comum a todo Dasein, dando-se, não obstante, na contingência da vida, de diferentes formas em cada indivíduo. É existenciário e não um categorial, isto é, não é uma essentia fechada em si mesma como um instinto animal, por exemplo.

\section{Considerações finais}

Pudemos perceber que o frutífero horizonte de pensamento irrompido da obra heideggeriana, assim como o seu diálogo com pensadores da área, pode abrir diversas perspectivas para se pensar a educação. Aqui

\footnotetext{
${ }^{7}$ Em O Mestre Ignorante - Cinco lições sobre a emancipação intelectual, Rancière conta a história do pedagogo francês Joseph Jacotot que no século XIX, propôs o ensino universal que, grosso modo, baseia-se no pressuposto da igualdade da inteligência entre os homens, assim como na premissa de que a função da educação é, ao invés da mera transmissão de conhecimento, despertar a consciência individual acerca da inteligência em ação em todos os homens.
} 
nada mais fizemos do que trazer à baila alguns apontamentos a serem eventualmente melhor percorridos e amadurecidos sobre a possível relação entre ontologia, poesia, espanto e ensino. Nosso desejo, assim sendo, tange à busca por pensar através de uma conversa com o leitor formas mais vivas de uma prática educativa fundada, por sua vez, num entendimento ontológico do que é ensinar e aprender.

$\mathrm{Na}$ concepção aqui delineada, o homem ou melhor o Dasein é considerado especificamente através de sua abertura para o ser, sendo a existência (ex-sistere) sua própria abertura. O conhecimento, do mesmo modo, torna- se, fundamentalmente, um conhecer dos múltiplos sentidos do ser abrindo margem para uma compreensão do constitutivo inacabamento de nosso próprio entendimento. A educação, por sua vez, torna-se espanto e poesia, travessia, profunda experiência que nos atravessa ao propor questões sobre o mundo, sobre o outro e sobre nós mesmos, queremos dizer, transmuta-se em um tornar-se si mesmo a partir das possibilidades de nosso mundo e de nossa história.

Acreditamos que a pequena e incipiente reflexão desse ensaio pode contribuir para ajudar, a partir do (re)pensar do leitor, a libertar cada vez mais a prática pedagógica da arrogância dos modos totalizadores e dogmáticos de ensino ainda presentes através de uma elucidação daquilo que efetivamente somos, um ente aberto para as suas possibilidades e, assim, jamais concluído e repetível; não uma substância, um modo de ser fechado sobre si mesmo, mas um existente, ente aberto para o vir-a-ser. Já que temos, no campo de nossos apontamentos, um mar bravio e ainda bastante convidativo a ser explorado que suas ondas nos conduzam ao solo de uma educação que seja poesia e de uma poesia que seja educação.

\section{Referências}

ARISTÓTELES. Metafísica. São Paulo: Edições Loyola, 2002.

FREIRE, Paulo. Pedagogia da Autonomia. São Paulo: Paz e Terra, 2007. . Pedagogia do Oprimido. São Paulo: Paz e Terra, 2019. 
HEIDEGGER, Martin. A Essência do Fundamento. In: Marcas do Caminho. Petrópolis: Editora Vozes, 2008a.

- A Essência da Linguagem. In: A Caminho da Linguagem. Petrópolis/São Paulo: Editora Vozes/Editora Universitária São Francisco, 2003.

.. A Essência da verdade. In: Marcas do Caminho. Petrópolis: Editora Vozes, 2008b.

.. A Origem da Obra de Arte. In: Caminhos de Floresta. Lisboa: Fundação Calouste Gulbenkian, 2014a.

.. A Questão da Técnica. In: Ensaios e Conferências. Petrópolis: Editora

Vozes, 2002a.

.. Carta Sobre o Humanismo. In: Marcas do Caminho. Petrópolis:

Editora Vozes, 2008c.

. Ciência e Pensamento do Sentido. In: Ensaios e conferências. Petrópolis:

Editora Vozes, 2002c

.. Identidade e Diferença. In: Conferências e Escritos Filosóficos. São Paulo:

Editora Nova Cultural, 1999.

.. O Tempo da Imagem no Mundo. In: Caminhos de Floresta. Lisboa: Fundação Calouste Gulbenkian, 2014b.

.. O que quer dizerer pensar? In: Ensaios e Conferências. Petrópolis: Editora Vozes, 2002b.

.. O que é Metafísica? In: Marcas do Caminho. Petrópolis: Vozes, 2008d.

.. Poeticamente o homem habita. In: Ensaios e Conferências. Petrópolis:

Editora Vozes, 2002d.

. Seminários de Zollikon. Petrópolis: Editora Vozes, 2001.

.. Ser e Tempo. Col. Multilíngues de Filosofia Unicamp. 1 ${ }^{\mathrm{a}}$ reimpressão. Trad. Fausto Castilho. Petrópolis: Vozes, 2014c.

KAHLMEYER-MERTENS, Roberto. Heidegger e a Educação. Belo Horizonte: Autêntica Editora, 2008.

LARROSA, Jorge. Pedagogia Profana - Danças, piruetas e mascaradas. Belo Horizonte: Editora Autêntica, 2017. .. Notas Sobre a Experiência e o Saber de Experiência. Revista Brasileira de Educação. Abril, 2002, nº 19, p.20-28. 
MASSCHELEIN, Jan; SIMONS, Maarten. Em defesa da escola - Uma questão pública. Belo Horizonte: Autêntica Editora, 2013.

RANCIÈRE, Jacques. O Mestre Ignorante - Cinco lições sobre a emancipação intelectual. Belo Horizonte: Autêntica Editora, 2002.

SAVIANI, Dermeval. Escola e Democracia: Polêmicas de nosso tempo. Campinas: Autores Associados, 1985.

SLOTERDIJT, Peter. Regras para o parque bumano - Uma resposta à carta de Heidegger sobre o humanismo. São Paulo: Estação Liberdade, 2000.

ZARADER, Marlène. Heidegger e As Palavras da Origem. Lisboa: Instituto Piaget, 1999.

Submetido em: $17 / 11 / 2020$

Aceito em: 22/04/2021

Publicado em: 12/05/2021 